\title{
A STUDY OF CORRELATION BETWEEN THE ECG CHANGES WITH THE DURATION AND SEVERITY OF CHRONIC OBSTRUCTIVE PULMONARY DISEASE
}

\author{
Jitendra Jain ${ }^{1}$, S. Apte ${ }^{2}$, P. Soni ${ }^{3}$, R. Chanchlani ${ }^{4}$
}

\section{HOW TO CITE THIS ARTICLE:}

Jitendra Jain, S. Apte, P. Soni, R. Chanchlani. "A Study of Correlation between the ECG changes with the duration and Severity of Chronic Obstructive Pulmonary Disease". Journal of Evolution of Medical and Dental Sciences 2014; Vol. 3, Issue 07, February 17; Page: 1739-1744, DOI: 10.14260/jemds/2014/2051

ABSTRACT: INTRODUCTION: Chronic obstructive pulmonary disease (COPD) is a major cause of morbidity and mortality in India especially in rural areas. COPD is the 5th leading cause of death worldwide. COPD causes hypoxia in lungs triggering the pulmonary vasoconstriction which leads to increase in pulmonary vascular resistance finally involving the heart and causes right sided cardiac complications which can be evidenced by Electrocardiography (ECG). Therefore, the present study was conducted to evaluate the diagnostic values of ECG changes among COPD patients. MATERIAL AND METHODS: This was a cross-sectional study done in the Medicine department of Chirayu Medical College and Hospital, Bhopal during the period from January 2012 to June 2012. 60 cases of COPD were selected for study. The diagnosis of COPD is based upon the clinical history, clinical examination, X-ray chest and Pulmonary Function Test (PFT). ECG was done in all the 60 patients and looked for heart axis, Right Ventricular Enlargement (RVE), Right Atrial Enlargement (RAE) and Right Bundle Branch Block (RBBB). RESULTS: ECG analysis shows the features suggestive of RAE in $>40 \%$ of COPD patients having duration of $>10$ yrs. Out of total 60 patients 24 patients had Forced Expiratory Volume First(FEV1) $\geq 80 \%$ (mild COPD), 30 had FEV1 $50 \%$ to 79\% (moderate COPD), 5 patients had FEV1 30-49\% (severe COPD) and 1 patient had FEV1 < 30\% (very severe COPD). When the disease severity is compared with the Manifestations in ECG RAE, RVE and RBBB was found in 3 $(60 \%)$ of the patients out of 5 patients who had severe disease. CONCLUSION: The prevalence of ECG abnormalities related to cardiac diseases, in general is higher in those with more severe pulmonary obstruction and ECG findings should be taken into consideration when diagnosing these patients of COPD for delivering a more integrated pulmonary and cardiovascular care.

KEYWORDS: Chronic obstructive pulmonary disease, Electrocardiography, Right Atrial Enlargement, Right Bundle Branch Block, Right Ventricular Enlargement.

INTRODUCTION: COPD (Chronic obstructive pulmonary disease) is a major cause of morbidity and mortality in India especially in rural areas. COPD is the 5th leading cause of death worldwide. ${ }^{1,2}$ COPD causes hypoxia in lungs triggering the pulmonary vasoconstriction which leads to increase in pulmonary vascular resistance finally involving the heart and causes right sided cardiac complications which can be evidenced by ECG. The patients with COPD are unable to perform physical activity and suffer from poor quality of life. ${ }^{3}$ Smoking cessation for 20 years almost completely reduce the risk of COPD due to smoking. ${ }^{4}$ Varied prevalence of COPD among adult population is reported in India. ${ }^{5-9}$ Several studies reported changes in the activity of heart including P-wave axis and amplitude, rightward displacement of QRS and T-axis, reduction of amplitude of QRS complex in limb and precordial leads, sinus tachycardia, Right bundle branch block (RBBB) etc., among COPD patients. However, COPD patients probably are not usually assessed by 
electrocardiogram in routine medical practice particularly in developing countries like India. Therefore, the present study was conducted to evaluate the diagnostic values of ECG changes among COPD patients.

MATERIAL AND METHODS: This was a cross-sectional study done in the Medicine department of Chirayu Medical College and Hospital, Bhopal during the period from January 2012 to June 2012. A total of 60 study subjects fulfilling the inclusion criteria and consenting to participate were included in the study. The diagnosis of COPD is based upon the clinical history, clinical examination, X-ray chest and PFT. Almost all the cases have varying degrees of overlapping picture of chronic bronchitis and emphysema taken as single entity of COPD. Patients under study were thoroughly asked for age, sex, occupation, Smoking habits and sign and symptoms of COPD. Apart from the specific investigation to diagnosis of COPD routine investigation performed in each patient was CBC + ESR, Urine- routine \& microscope. ECG was done in all the 60 patients and looked for heart axis, RVH \& RAE and RBBB.

RESULTS: Out of 60 patients, maximum number of patients is in age group 51-60 (36.67\%). Mean age is 53 years. There is male predominance over females in this study, showing a ratio of 5:1. Maximum numbers of patients have duration of illness of 5-10 years (33-33\%) closely followed by 10-20 years (30\%). Mean duration of illness is 12.7 years (Table no. 1). Smoking habits in males having COPD are 20 times more than in females, though COPD patients who are non-smokers are almost equal. Cough with expectoration is the predominant symptom in $>80 \%$ of COPD patients (Table no. 2). On clinical examination - Coarse crackles are found in $>90 \%$ of the patients followed by cyanosis, edema $\&$ hepatomegaly in about $50 \%$ of the patients (Table no. 3). About $30 \%$ of COPD patients in ECG show features of RAE \& RVE. RAE was found in 20 (33.33\%) subjects, RVE in 22 (36\%), RAD in 16 $(26.67 \%)$ and RBBB was found in 22 (36\%) of patients. (Table no. 4). ECG analysis shows the features suggestive of right atrial enlargement in $>40 \%$ of COPD patients having duration of $>10 \mathrm{yrs}$. RAE, RVE and RBBB was found in $>50 \%$ of the patients of duration of illness more than 10 years which shows that as the duration of COPD increases the chances of getting ECG changes are more (Table no. 5). Out of total 60 patients 24 patients had Forced Expiratory Volume First (FEV1) $\geq 80 \%$ (mild COPD), 30 had FEV1 $50 \%$ to 79\% (moderate COPD), 5 patients had FEV1 30-49\% (severe COPD) and 1 patient had FEV1 < 30\% (very severe COPD). When the disease severity is compared with the Manifestations in ECG RAE, RVE and RBBB was found in $3(60 \%)$ of the patients out of 5 patients who had severe disease, details of the patients according to the severity of the illness and ECG manifestations in COPD is given in Table no. 6.

DISCUSSION: A study of Electro cardiogram (ECG) in 60 patients primarily suffering from chronic obstructive pulmonary disease (COPD) is done. In present study Cough with expectoration is the predominant symptom in $>80 \%$ of COPD patients followed by fever $80 \%$ and breathlessness $66.6 \%$. Coarse crackles are found in $>90 \%$ of the patients followed by cyanosis, edema \& hepatomegaly in about $50 \%$ of the patients whereas in the study of Sharma R et.al. done in 2013 in Moradabad cough with expectoration was found in all patients, breathlessness was present in $95 \%$ of cases, clubbing in 3 patients, pedal edema in 8 cases. ${ }^{10}$ 
In our study RAE was found in 20 (33.33\%) subjects, RVE in 22 (36\%), RAD in 16 (26.67\%) and RBBB was found in 22 (36\%) of patients. In the study done in 2013 in Moradabad RAE was found in $18(40 \%)$ and RBBB was found in $1(2.5 \%)$ of the total 40 patients. ${ }^{10}$ Whereas in another study done by Miriam J. Warnier and Frans H. et.al in 2013 RAE was found in 3(1\%), RVE in 1(3\%) and RBBB was found in $17(7 \%)$ of patients. ${ }^{11}$ In another study done by Hina Banker et.al in 2011 RAD was found in $70(70 \%)$, RAE in $35(35 \%)$ and RBBB was found in $12(12 \%)$ of the total 100 patients. $^{12}$

In our study RAE, RVE and RBBB was found in $>50 \%$ of the patients of duration of illness more than 10 years which is similar to the findings of the study done by Jimnaz PA in Mangalore in 2010.13

In our study 24 patients were found to have mild COPD, 30 had moderate COPD, 5 patients had severe COPD and 1 patient had very severe COPD out of total 30 patients. The patient who had very severe COPD had shown all the changes in the ECG as RAE, RVE, RAD, RBBB. Out of total 5 patients who had severe disease RAE, RVE and RBBB were found in 3(60\%). Out of total 30 patients who had moderate disease RAE was found in 14 (46.6\%), RVE and RBBB was found in 12 and RAD was found in $8(26.6 \%)$ of the patients. Out of total 24 patients who had mild disease RAE was found in $2(8.3 \%)$, RVE, RAD and RBBB was found in 6 and was found in $8(25 \%)$ of the patients whereas in another study of Holtzman D et.al Right atrial enlargement (RAE) occurred in 44\% of patients with severe disease and $15 \%$ of patients with mild to moderate disease. Right ventricular hypertrophy $(\mathrm{RVH})$ occurred in $29 \%$ of patients with severe disease and $4 \%$ of patients with mild to moderate disease. Right bundle branch block (RBBB) occurred in 29\% of patients with severe disease and 11\% of patients with mild to moderate disease. Marked clockwise rotation of heart occurred in $40 \%$ of patients with severe disease and $18 \%$ of patients with mild to moderate disease. ${ }^{14}$

CONCLUSION: We conclude that electrocardiographic abnormalities, particularly conduction abnormalities, are common in patients with chronic obstructive pulmonary disease. The prevalence of ECG abnormalities related to cardiac diseases, in general, is higher in those with more severe pulmonary obstruction. Previous studies suggest that COPD is related with cardiovascular morbidity and mortality. Our results show that COPD patients more often have ECG abnormalities, including abnormalities that have been shown to increase the risk of future cardiovascular events and mortality. 15-17 Therefore; ECG findings should be taken into consideration when diagnosing these patients of COPD for delivering a more integrated pulmonary and cardiovascular care.

\section{REFERENCES:}

1. Joshi $\mathrm{R}$, Cardona $\mathrm{M}$, Iyengar $\mathrm{S}$ et al. Chronic diseases now a leading cause of death in rural India-Mortality data from the Andhra Pradesh Rural Health Initiative. Int. J. Epidemiol 2006; 35(6): 1522-29.

2. Lamprecht B, McBurnie MA, Vollmer WM, et al. COPD in never smokers: results from the population-based burden of obstructive lung disease study. Chest 2011; 139: 752-63.

3. Mats Arne, Christer Janson, Staffan Janson, Physical activity and quality of life in subjects with chronic disease: Chronic obstructive pulmonary disease compared with rheumatoid arthritis and diabetes mellitus. Scand J Prim Healthcare 2009; 27(3): 141-147.

4. Godtfredsen N., S, Lam T. H., Hansel T. T. COPD-related morbidity and mortality after smoking cessation: status of the evidence N. S., European Respiratory Journal 2008; 32(4): 844-853. 
5. Jindal SK, Agarwal AN, Gupta D. A review of population studies from India to estimate national burden of chronic obstructive pulmonary disease and its association with smoking. Indian J Chest Dis Allied Sci 2001; 43:139-47.

6. Bhattacharya SN, Bhatnagar JK, Kumar S, Jain PC. Chronic bronchitis in rural population. Indian J Chest Dis 1975; 17:1-7.

7. Malik SK. Profile chronic bronchitis in North India: The PGI experience (1972-1985). Lung India 1986; 4:89-100.

8. Jindal SK. A profile study on follows up at 10 years of prevalence of chronic obstructive pulmonary disease and peak expiratory flow rate. Indian J Med Res (B) 1993; 98:20-26.

9. Ray D, Abel R. A 5 year prospective epidemiological study of chronic obstructive pulmonary disease in rural South India. Indian J Med Res 1995; 101:238-44.

10. Sharma RA, Hashim Z, Sharma E, Hashim T, Sharma T. Diagnosis of severity of COPD on the basis of electrocardiogram. Indian Journal of Basic \& Applied Medical Research 2013: Issue-6, Vol.-2, P. 527-530

11. Miriam J. Warnier, Frans H. Rutten, Mattijs E. Numans, Jan A. Kors, Hanno L.Tan, Anthonius de Boer, Arno W. Hoes, and Marie L. De Bruin. Electrocardiographic Characteristics of Patients with Chronic Obstructive Pulmonary Disease. Journal of COPD 2013, 10:62-71.

12. Banker H, Verma A. Electrocardiographic changes in COPD. NHL Journal of Medical Sciences 2013/Vol; 2(2).

13. Jimnaz PA. A prospective study of electrocardiographic changes in COPD patients. url: http//www.jspui/bitstream/123456789/1404/1/CDMGENM00321.pdf

14. Holtzman D, Aronow WS, Mellana WM, Sharma M, Mehta N, Lim J, et al. Electrocardiographic abnormalities in patients with severe versus mild or moderate chronic obstructive pulmonary disease followed in an academic outpatient pulmonary clinic. Ann Noninvas Electrocardiol 2011; 16(1):30-32.

15. Fox K, Borer JS, Camm AJ, Danchin N, Ferrari R, Lopez Sendon JL, et al. Resting heart rate in cardiovascular disease. J Am Coll Cardiol 2007; 50(9):823-830.

16. Lewinter C, Torp Pedersen C, Cleland JGF, Kber L. Right and left bundle branch block as predictors of long-term mortality following myocardial infarction. Euro J Heart Fail 2011; 13(12):1349-1354.

17. Zhang Y, Post W, Dalal D, Blasco Colmenares E, Tomaselli G, Guallar E. QT-interval duration and mortality rate: results from the Third National Health and Nutrition Examination Survey. Arch Intern Med 2011; 171(19): 1727-33.

\begin{tabular}{|c|c|c|}
\hline Duration of illness & No. of patients & Percentage (\%) \\
\hline$<5$ yrs. & 12 & 20.00 \\
\hline $5-10$ yrs & 20 & 33.33 \\
\hline $10-20$ yrs & 18 & 30.00 \\
\hline$<20$ yrs & 10 & 16.67 \\
\hline
\end{tabular}

Table no. 1: Distribution of the patients according to the duration of the illness 


\begin{tabular}{|l|c|c|}
\hline \multicolumn{1}{|c|}{ Symptoms } & No. of patients & Percentage (\%) \\
\hline Cough with expectoration & 50 & 83.33 \\
\hline Breathlessness & 40 & 66.67 \\
\hline Cough + Breathlessness & 36 & 60.00 \\
\hline Chest pain & 10 & 16.67 \\
\hline Fever & 48 & 80.00
\end{tabular}

Table no. 2: Distribution of the patients according to the presenting symptoms of the illness (multiple responses)

\begin{tabular}{|l|c|c|}
\hline \multicolumn{1}{|c|}{ Clinical Signs } & No. of patients & Percentage (\%) \\
\hline Pallor & 20 & 33.33 \\
\hline Cyanosis & 30 & 50.00 \\
\hline Edema & 30 & 50.00 \\
\hline Hepatomegaly & 30 & 50.00 \\
\hline Raised JVP & 20 & 33.33 \\
\hline Crackles & 56 & 93.33 \\
\hline Poor air entry & 12 & 20.00 \\
\hline Signs of hyperinflation & 36 & 60.00 \\
\hline \multicolumn{2}{|c|}{ Table no. 3: Distribution of the patients according } \\
to the clinical signs of the illness (multiple responses) \\
\hline
\end{tabular}

\begin{tabular}{|c|c|c|}
\hline ECG changes & No. of patients & Percentage (\%) \\
\hline RAE & 20 & 33.33 \\
\hline RVE & 22 & 36.67 \\
\hline RAE + RVE & 20 & 33.37 \\
\hline Right Axis Deviation & 16 & 26.67 \\
\hline RBBB & 22 & 36.67 \\
Table no. 4: Distribution of the patients \\
according to the ECG manifestations in COPD
\end{tabular}

\begin{tabular}{|c|c|c|c|c|}
\hline Duration of Illness & $\begin{array}{c}\text { RAE } \\
(\mathbf{n = 2 0 )}\end{array}$ & $\begin{array}{c}\text { RVE } \\
\text { (n=22) }\end{array}$ & $\begin{array}{c}\text { Rt. Axis. Dev. } \\
\text { (n=16) }\end{array}$ & $\begin{array}{c}\text { RBBB } \\
\text { (n=22) }\end{array}$ \\
\hline$<5$ yrs. & $02(10 \%)$ & $04(18.1 \%)$ & $02(12.5 \%)$ & $04(18.1 \%)$ \\
\hline $5-10$ yrs & $04(20 \%)$ & $08(36.3 \%)$ & $06(37.5 \%)$ & $06(27.2 \%)$ \\
\hline $10-20$ yrs & $08(40 \%)$ & $06(27.2 \%)$ & $06(37.5 \%)$ & $06(27.2 \%)$ \\
\hline$<20$ yrs & $06(30 \%)$ & $04(27.2 \%)$ & $02(12.5 \%)$ & $06(27.2 \%)$ \\
\hline Total & $20(100 \%)$ & $22(100 \%)$ & $16(100 \%)$ & $22(100 \%)$ \\
\hline
\end{tabular}

Table no. 5: Distribution of the patients according to the duration of the illness and ECG manifestations in COPD 


\begin{tabular}{|c|c|c|c|c|c|c|c|c|}
\hline \multirow{3}{*}{$\begin{array}{c}\text { FEV1 } \\
\text { (Severity of the illness) }\end{array}$} & \multicolumn{8}{|c|}{ ECG Changes } \\
\hline & \multicolumn{2}{|c|}{ RAE } & \multicolumn{2}{|c|}{ RVE } & \multicolumn{2}{|c|}{ RAD } & \multicolumn{2}{|c|}{ RBBB } \\
\hline & No. & $\%$ & No. & $\%$ & No. & $\%$ & No. & $\%$ \\
\hline$<30 \%$ (very severe) $(n=1)$ & 01 & 100 & 01 & 100 & 01 & 100 & 01 & 100 \\
\hline $30-49 \%($ severe $)(n=5)$ & 03 & 60.00 & 03 & 60.00 & 01 & 20.00 & 03 & 60.00 \\
\hline $50-79 \%$ (moderate) $(n=30)$ & 14 & 46.67 & 12 & 40 & 08 & 26.67 & 12 & 40 \\
\hline$>80 \%$ (mild) $(\mathrm{n}=24)$ & 02 & 8.33 & 06 & 25 & 06 & 25 & 06 & 25 \\
\hline
\end{tabular}

\section{AUTHORS:}

1. Jitendra Jain

2. S. Apte

3. P. Soni

4. R. Chanchlani

\section{PARTICULARS OF CONTRIBUTORS:}

1. Associate Professor, Department of Medicine, Chirayu Medical College and Hospital, Bhopal.

2. Associate Professor, Department of Medicine, Chirayu Medical College and Hospital, Bhopal.

3. Assistant Professor, Department of Medicine, Chirayu Medical College and Hospital, Bhopal.

4. Associate Professor, Department of Surgery, Chirayu Medical College and Hospital, Bhopal.

\section{NAME ADDRESS EMAIL ID OF THE CORRESPONDING AUTHOR:}

Dr. Roshan Chanchlani, 1/6-Idgah Kothi, Doctors Enclave, Near Filter Plant, Idgah Hills, Bhopal, (M.P) - 462001.

E-mail: roshanchanchlani@gmail.com

Date of Submission: 20/01/2014. Date of Peer Review: 21/01/2014. Date of Acceptance: 30/01/2014. Date of Publishing: 14/02/2014. 